\title{
Os gêneros de texto na dinâmica das práticas de linguagem
}

Florencia Miranda*

\author{
Universidad Nacional \\ de Rosario (Argentina); \\ Centro de Linguística da \\ Universidade Nova de \\ RESUMO \\ Lisboa - FCT (Portugal).
}

A noção de gênero (textual ou discursivo) ocupa um lugar importante em diferentes abordagens no interior das Ciências da Linguagem à medida que os gêneros são concebidos como formas relativamente estáveis que estabelecem os nexos entre os textos singulares e as atividades da vida social. Porém, as relações entre os gêneros e as atividades são objeto de discussão entre as diversas posições científicas. Este artigo procura contribuir para esse debate tomando como ponto de partida um diálogo crítico entre a semântica textual de François Rastier e o interacionismo sociodiscursivo de JeanPaul Bronckart e através da análise de três textos. Seu objetivo central é demonstrar que não se pode estabelecer relações biunívocas e simples entre gêneros e atividades práticas, pois diversas atividades podem estar implicadas em um único gênero e, reciprocamente, um mesmo gênero pode ser mobilizado em diferentes atividades da vida social.

PALAVRAS-CHAVE

Gêneros de texto. Gêneros de dicurso. Atividade de linguagem. Interacionismo sociodiscursivo. Semântica textual. 


\section{PONTO DE PARTIDA}

A noção de gênero (textual ou discursivo, dependendo da perspectiva teórica) vem ocupando um lugar cada vez mais central no complexo panorama das Ciências da Linguagem, sendo notável, também, seu impacto no campo do ensino de línguas. Dentre as variadas correntes que têm contribuído de forma significativa no debate sobre essa noção se destaca o Interacionismo Sociodiscursivo (doravante ISD).

O ISD é uma corrente que se inscreve no interacionismo social (na esteira de Voloshinov, Vigotsky e Mead, por exemplo). Desenvolvido inicialmente e desde os anos 1980 na unidade de Didática de Línguas da Universidade de Genebra, por uma equipe coordenada por Jean-Paul Bronckart, o ISD é hoje um espaço de pensamento, estudo e intervenção onde confluem as práticas de pesquisadores e profissionais da linguagem de diferentes países.

No âmbito do ISD, os gêneros são concebidos como formatos textuais relativamente estabilizados - e, portanto, dinâmicos - que se associam a diversas atividades de linguagem (ou, em termos bakhtinianos - a diferentes “esferas de utilização da língua”). São atividades sociais e de linguagem, tais como a familiar, a jornalística, a publicitária, a administrativa, a literária, a jurídica, a comercial, etc. Os gêneros funcionam como instrumentos ou modelos psicossociolinguísticos aos quais se recorrem necessariamente para a produção e a interpretação de qualquer texto (MIRANDA, 2010).

O objetivo deste ensaio é colocar um problema teórico-metodológico e, nesse sentido, mostrar um ponto de vista sobre a problemática dos gêneros de texto nas práticas de linguagem. Para tanto, e dado que o ISD é uma corrente teórica que tem interesse sempre em dialogar com outras correntes, inciarei a minha reflexão retomando algumas considerações que Bronckart formulou em um trabalho elaborado como base para sua conferência no II Encontro do ISD, realizado em Lisboa em 2007 - trabalho esse que foi publicado depois na revista digital Texto! em janeiro de 2008. Escolho esse trabalho não só pelo fato de ser um trabalho relevante, mas também porque é um claro exemplo de diálogo entre teorias: especificamente o ISD e a Semântica Textual desenvolvida por François Rastier (cf. RASTIER, 1989 e 2001).

Retomando as próprias palavras de Bronckart, estas duas perspectivas têm em comum o fato de assumirem que o objeto primário das Ciências da Linguagem é constituído pelos textos, porque se trata das realizações empíricas da linguagem. Além disso, em ambas as perspectivas se assume 
que os textos devem ser observados na sua condição de gênero, porque essa condição é o lugar em que se manifestam as relações de interdependência entre as propriedades dos textos e as propriedades das atividades sociais em que são produzidos (BRONCKART, 2008, p. 39).

Esse ponto de contato entre ambas as perspectivas tem evidentemente implicações metodológicas convergentes: na linha do ISD, já se tem explicitado reiteradamente que se assume, na vertente de Voloshinov, ${ }^{1}$ uma abordagem descendente (das atividades sociais ou coletivas e das atividades de linguagem para os textos, dos textos para as unidades linguísticas - cf., por exemplo, (BRONCKART, 2004a, p. 104)); da mesma forma, Rastier (2001, p. 13) insiste em que a abordagem deve sempre se orientar do global para o local.

Concordando, então, com essa forma de conceber a metodologia de análise, quando abordamos um texto (ou um conjunto de textos) o primeiro questionamento deve orientar-se para o âmbito da atividade. Em princípio, nada parece mais pacífico do que isso. No entanto, como veremos, a identificação das propriedades desse âmbito constitui um sério problema metodológico e implica a necessidade de clarificar as relações entre os gêneros e as diversas espécies de atividades de linguagem.

\section{O PROBLEMA DA RELAÇÃO ENTRE GÊNEROS E ATIVIDADES DE LINGUAGEM}

Voltando ao trabalho de Bronckart (2008) sobre a perspectiva de Rastier, no capítulo dedicado à discussão acerca dos textos no seu envolvimento social (capítulo II), Bronckart observa o modo como Rastier apresenta as interações entre o registro praxeológico e o registro linguístico. É preciso mencionar desde já que o emprego do termo “discurso" na perspectiva de Rastier é equivalente à noção de "atividade de linguagem" assumida no ISD, de modo que aquilo que, para Rastier, são os "tipos de discurso", para Bronckart são

\footnotetext{
Vejam-se as seguintes palavras de Voloshinov: "El lenguaje vive y se genera históricamente en la comunicación discursiva concreta, y no en un sistema lingüístico abstracto de formas, ni tampoco en la psique individual de los hablantes. Por consiguiente, un orden metodológicamente fundado del estudio del lenguaje debe ser el siguiente: 1) formas y tipos de interacción discursiva en relación con sus condiciones concretas; 2) formas de enunciados concretos, de algunas actuaciones discursivas en estrecha relación con la interacción cuyos elementos son estos enunciados, esto es, los géneros de las actuaciones discursivas (...); 3) a partir de ahí, una revisión de las formas del lenguaje tomadas en su versión lingüística habitual” (VOLOSHINOV [1929] 2009, p. 155)
} 
as diversas "espécies de atividades de linguagem" (associadas a atividades práticas diversificadas).

Na perspectiva de Rastier, a cada tipo de prática social corresponde um tipo de discurso. ${ }^{3}$ Cada prática social se divide em atividades específicas às quais corresponde um sistema de gêneros em coevolução; portanto, os gêneros são específicos aos discursos. Além disso, Rastier propõe a noção de campo genérico para dar conta de grupos de gêneros que contrastam no interior de um mesmo domínio de atividade. Isto é sintetizado no seguinte esquema:

\begin{tabular}{|c|c|c|c|c|}
\hline Praxeologia & Domínio de atividade & Campo prático & Prática & Curso de ação \\
\hline Linguística & Discurso & Campo genérico & Gênero & Texto \\
\hline
\end{tabular}

Para ilustrar o funcionamento das noções, um dos exemplos que Rastier propõe é o caso da literatura (como domínio de atividade e como discurso), em que, por exemplo, o campo genérico do teatro se divide em comédia e tragédia. Dentre os diversos comentários que Bronckart realiza, referirei apenas (e brevemente) duas questões: por um lado, a questão da correspondência entre as noções dos dois registros e, por outro, a noção de campo genérico.

Bronckart questiona a apresentação do esquema porque parece mostrar uma correspondência biunívoca entre os componentes dos dois registros. Nesse sentido, diz Bronckart (2008, p.43), não se estaria considerando o fato de que diversos gêneros podem corresponder a uma mesma prática ou que gêneros elaborados no quadro de um determinado campo prático possam ser reutilizados e reelaborados depois em outros campos e em outras práticas singulares. É sobre esta questão, sobretudo, que me proponho a refletir no presente ensaio.

Todavia, antes disso interessa observar também que Bronckart duvida inicialmente do emprego da noção de campo genérico (cf. BRONCKART, 2008, p. 43), porque considera que talvez não seja apropriada para dar conta de todos os campos práticos (funciona na literatura, funciona no campo jurídico, mas seria preciso verificar se funciona em outros campos). Apesar disso, Bronckart integra finalmente essa noção em um esquema em que reformula as relações entre os dois registros (BRONCKART, 2008, p. 45).

Sobre este ponto, cabe, porém, observar que para Bronckart as atividades de linguagem são da ordem do praxeológico e não do linguístico e que o autor rejeita a ideia de uma possível identificação de "tipos de discurso" (ou de espécies de atividades de linguagem) na base de critérios linguísticos. Para uma discussão sobre as diferentes opções terminológicas/epistemológicas, ver BRONCKART (2004a) e BRONCKART (2008), entre outros.

Vale explicitar que o emprego do termo "tipo", discutível porque não se trata de fato de uma tipologia, é do próprio autor. 


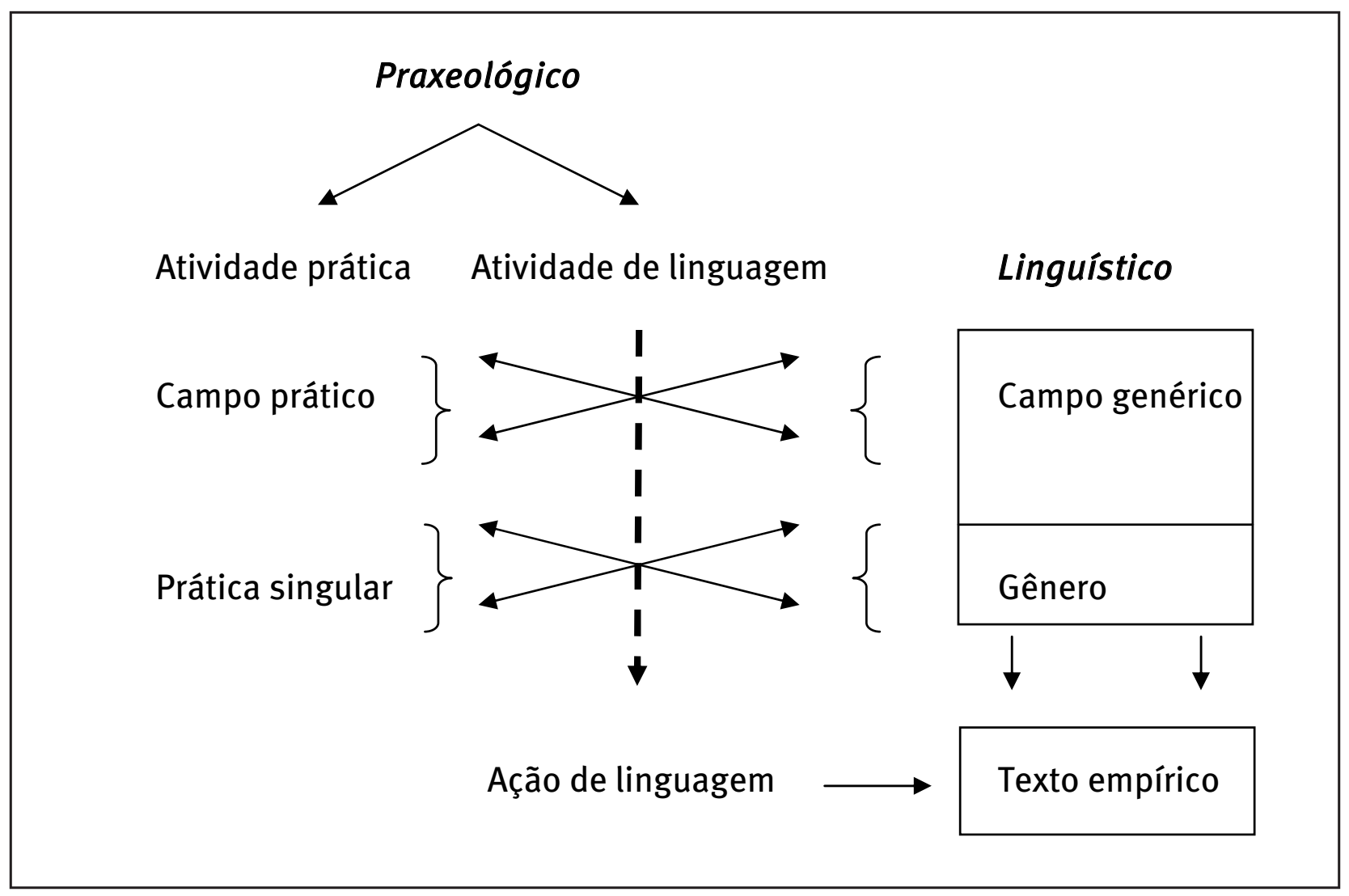

$\mathrm{Na}$ explicação do esquema, Bronckart indica que o recurso às setas entrecruzadas visa a mostrar a complexidade, a mobilidade e os efeitos de ida e volta que se produzem no curso do tempo entre a ordem das práticas e a ordem dos gêneros. É justamente esta dinâmica, a meu ver, que às vezes parece ser difícil de apreender e de caracterizar.

\section{UM EXEMPLO DE TRATAMENTO TEÓRICO DA RELAÇÃO ENTRE GÊNEROS E ATIVIDADES}

Antes de observarmos alguns textos empíricos que nos permitirão problematizar mais ainda essa questão, proponho a observação de um exemplo de tratamento teórico da relação entre gêneros e atividades. Para isso, escolhi a apresentação desta problemática em um livro de Luiz Antônio Marcuschi (2008). Optei por essa apresentação, não só pela indiscutível qualidade da produção científica desse querido linguista, mas sobretudo porque se trata de uma obra que reúne os documentos de apoio utilizados pelo autor em um curso de linguística ao nível da Graduação em Letras. Isto implica que se trata de materiais dirigidos para os linguistas em formação.

Aqui também é preciso especificar uma equivalência terminológica: para as diversas atividades de linguagem associadas à diversidade de atividades 
práticas Marcuschi (2008, p.155) utiliza a expressão “domínio discursivo” que define nos seguintes termos:

Domínio discursivo constitui muito mais uma "esfera da atividade humana" no sentido bakhtiniano do termo do que um princípio de classificação de textos e indica instâncias discursivas (por exemplo: discurso jurídico, discurso jornalístico, discurso religioso, etc.). Não abrange um gênero em particular, mas dá origem a vários deles, já que os gêneros são institucionalmente marcados. Constituem práticas discursivas nas quais podemos identificar um conjunto de gêneros textuais que às vezes lhe são próprios ou específicos como rotinas comunicativas institucionalizadas e instauradoras de relações de poder.

Apesar das considerações expressas nessa definição, Marcuschi encara mais à frente na mesma obra o risco de uma tentativa de distribuição sistemática dos gêneros da oralidade e da escrita de acordo com os diversos domínios discursivos (cf. QUADRO 1).

Mesmo explicitando que não se propõe como uma classificação, que muitos gêneros são comuns a vários domínios e que se trata de uma listagem que não é definitiva nem representativa, o autor conclui que o quadro é revelador do fato de alguns domínios discursivos serem mais produtivos em diversidade genérica e outros mais resistentes (MARCUSCHI, 2008, p.196). Mas não é isso que me parece fundamental neste momento. Na verdade, e apesar de todas as ressalvas, a distribuição que o autor propõe como um instrumento para a análise dos gêneros coloca uma larga série de questões, entre outras: como é que se identificam esses domínios discursivos? Por que esses e não outros? Por que se utilizam essas designações? O que é que está em causa em cada um desses domínios? Veja-se, por exemplo, a designação “ficcional”: é equivalente a literatura? Abrange a literatura e outras formas ficcionais? Ou então, note-se a designação "instrucional" que envolve os campos científico, acadêmico e educacional. Em suma, como é possível pensar um critério de distinção dos domínios que permita colocar em um mesmo plano os campos jornalístico, comercial, jurídico, publicitário, etc. por um lado, e, por exemplo, o campo ficcional, por outro?

Além dessa questão, que não me parece menor, a lista dos gêneros no interior de cada domínio coloca mais questionamentos. Por que a receita culinária é considerada no domínio da saúde? Porque se relaciona com a alimentação? Por que os anúncios classificados e as cartas de leitor seriam do domínio jornalístico? Porque circulam em jornais? É então o suporte que define o campo? Por que o atestado de participação (em evento científico, infiro) se situa na esfera instrucional? Não corresponderia antes a um âmbito administrativo, por exemplo? E, por outro lado, esta distribuição dos gêneros não parece contemplar o fato de que aquilo que para mim (como leitora ou ouvinte) pode estar associado ao domínio do lazer (como as histórias em 
quadrinhos, os horóscopos, as palavras cruzadas e as piadas) correspondem a práticas profissionais (associadas à divisão do trabalho) para os seus autores.

QUADRO 1 - Gêneros textuais por domínios discursivos e modalidades

Domínios discursivos
Instrucional (cien-
tífico, acadêmico e
educacional)
Jornalístico

Religioso

Saúde

Comercial

Industrial

Jurídico

Publicitário

Lazer

Interpessoal

Militar

Ficcional
Modalidades de uso da língua

Escrita

\section{Oralidade}

Artigos científicos, verbetes de enciclopédias, relatórios científicos (...) solicitação de bolsa, cronograma de Conferências, debates (....) exames orais, exames finais, seminários de trabalho (...) certificado de proficiência, iniciantes (...) arguição atestado de participação (...) de tese (...)

Editoriais, notícias (...) jogos, histórias em quadrinhos (...), anúncios classificados (...), carta do leitor (...), cartum (...)

Orações, rezas, catecismo, homilias (...)

Entrevistas (...), notícias de rádio (...) boletim do tempo (...)

Sermões, confissão (...)

Receita médica, bula de remédio (...), receitas culinárias

Consulta, entrevista médica, conselho médico

Rótulo, nota de venda (...) carta comer- Publicidade de feira, pucial, parecer de consultoria (...) bilhete de avião, bilhete de ônibus (...) blicidade de tv (...), refrão de feira (...) Instruções de montagem, descrição de obras (...)

\section{Ordens}

Contratos, leis (...) certidão de casamento (...), edital de concurso (...), certificados, diplomas (...)

Tomada de depoimento, arguição, declarações (...)

Publicidade na tv, publicidade no rádio

Anúncios, cartazes, folhetos (...)

Piadas, jogos, adivinhas, histórias em quadrinhos, palavras cruzadas, horóscopo

Cartas pessoais, cartas comerciais (...), e-mail, bilhete (...) lista de compras (...)

Fofocas, piadas, adivinhas, jogos teatrais

Recados, conversações espontâneas, telefonemas (...)

Ordem do dia, roteiro de cerimônia oficial, roteiro de formatura, lista de Ordem do dia tarefas

Épica - lírica - dramática, poemas, contos (...), fábulas, histórias em quadrinhos, romances (...)
Fábulas, contos, lendas (...)

Fonte: MARCUSCHI, 2008, p.194-196

Todas estas questões demonstram que qualquer tentativa de sistematização 
das relações entre os gêneros e as atividades de linguagem tenderá a fracassar. Não dispomos de critérios claros para a distinção das diversas espécies de atividade, e em qualquer caso a relação entre atividades e gêneros não parece poder ser apreendida de modo estável e sistemático. Como explicita Bronckart (2006, p. 144):

não podemos estabelecer relação direta entre espécies de agir de linguagem e gêneros de textos, sendo as tentativas feitas nesse sentido decorrentes de uma adesão não crítica (ou excludente da história) às indexações sociais sincrônicas.

No entanto, é preciso admitir que este não é o caso de Marcuschi, que não exclui a vertente necessariamente dinâmica dessa relação. Em todo caso, há aqui um problema metodológico. Para o estudo dos gêneros e para a análise de textos precisamos enquadrar a produção e a compreensão de textos no âmbito das atividades coletivas. Além disso, parece ser necessário contar com categorias que permitam dar conta de grupos de gêneros que se relacionam quer no interior de um mesmo campo prático, quer na interação entre campos diversificados. Prova disto é o surgimento de categorias analíticas que diversos autores têm sugerido, por exemplo: campo genérico (RASTIER, 2001, retomada por BRONCKART, 2008), conjunto de gêneros (DEVITT, 1991, retomada por BAZERMAN, 2004, e BHATIA, 2004), sistema de gêneros (ADAMZIK, 1998, BAZERMAN, 2004), colônia da gêneros (BHATIA, 2004), etc.

\section{Problematizando a partir de textos empíricos}

Para completar esta problematização, proponho agora observar brevemente quatro textos empíricos. Os dois primeiros textos fazem parte do corpus do projeto Pretexto, desenvolvido por uma equipe de pesquisa no Centro de Linguística da Universidade Nova de Lisboa - projeto este a que se encontra ligado também um projeto pessoal de pesquisa de pós-doutorado -; os outros dois fazem parte do corpus sobre o qual trabalhei para a minha tese de doutorado. 


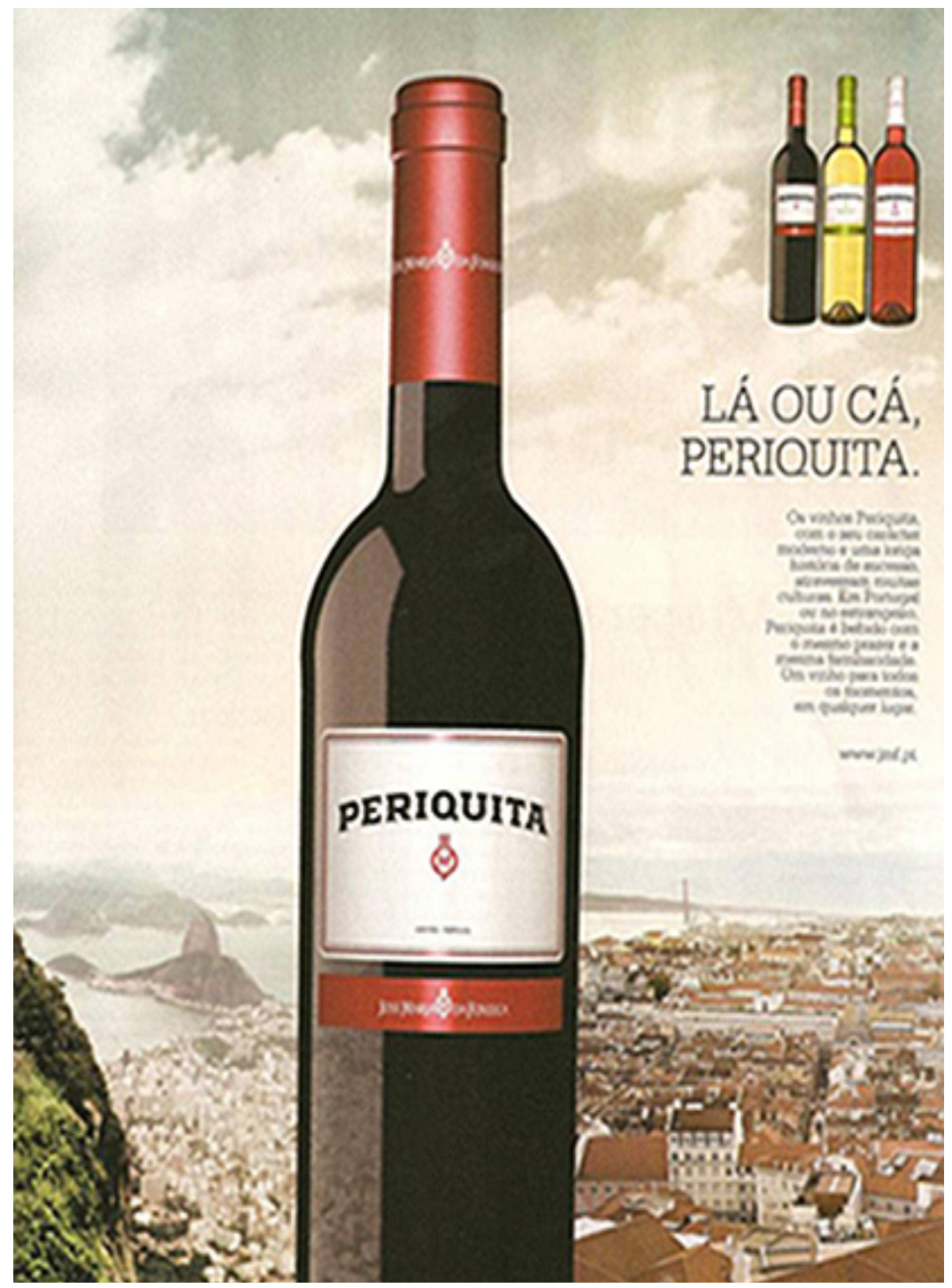

Texto (1)

O texto (1) é um anúncio publicitário do vinho português Periquita. Como é evidente, esse gênero não coloca realmente problemas no que diz respeito à sua inscrição em um campo de atividade. De fato, mesmo que os anúncios circulem em publicações jornalísticas, nenhum pesquisador duvidaria de que é um gênero que se inscreve plenamente na atividade publicitária e não na jornalística.

Esse exemplo permite mostrar que em certos casos a identificação do âmbito de atividade é relativamente pacífica e, na verdade, as questões mais profundas que esse gênero coloca dizem respeito à relação entre o gênero e o contexto de produção, ou melhor, entre o gênero e a "situação de ação de linguagem". Isso porque, por exemplo, se trata de um gênero produzido no quadro de uma ação conjunta (cf. BRONCKART, 2004b, p. 114), em que vários agentes produtores participam para a sua elaboração no curso do agir. 
Ora, por outro lado, interessará verificar que a atividade publicitária é uma prática complexa, na medida em que ela está controlada e regulamentada, isto é, é uma prática influenciada por diversas normativas e códigos. Por exemplo, no caso de Portugal existe especificamente um código da publicidade que regula essa prática. A questão mostra que também é preciso observar os modos como as diversas atividades interagem entre si.

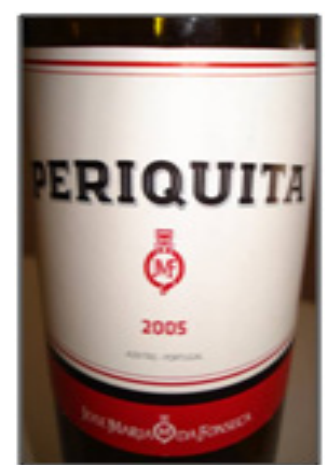

Texto (2) - parte 1

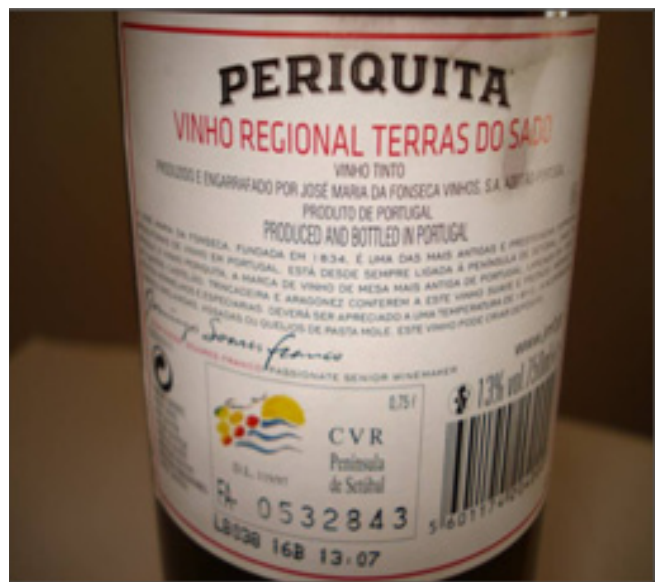

Texto (2) - parte 2

O texto (2), que se organiza em duas grandes partes, é um rótulo do mesmo vinho português publicado no texto (1). Se observarmos a sistematização proposta por Marcuschi, diremos que esse gênero se inscreve no domínio da atividade comercial. Todavia, além dessa inscrição indiscutível no domínio comercial, o gênero (à diferença de outros do mesmo domínio como a nota de venda, a carta comercial e o bilhete de avião) apresenta uma forte dimensão publicitária. De fato, grande parte do que se diz em um rótulo se orienta por essa finalidade publicitária. O rótulo não serve apenas para identificar um produto, mas também para provocar a compra do produto (cf. MIRANDA; COUTINHO, 2008). Isso implica que associar esse gênero somente à atividade comercial não permite dar conta do funcionamento social do gênero. Em 
consequência, o gênero não pode ser associado a uma única atividade (cf. MIRANDA, 2011).

Por outro lado, e segundo verificamos em diversas análises realizadas, uma característica recorrente, embora não obrigatória, desse gênero rótulo, quando se realiza em garrafas de vinho, é a ocorrência de uma unidade do plano do texto em que se incluem notas de degustação e recomendações de consumo e serviço (cf. MIRANDA; COUTINHO, 2008). Veja-se, nesse texto, por exemplo, o seguinte segmento:

\section{[...] As castas Castelão, Trincadeira e Aragonez conferem a este vinho suave e frutado, aromas a frutos vermelhos e especiarias. Deverá ser apreciado a uma temperatura de $16^{\circ} \mathrm{C}$., a acompanhar carnes grelhadas, assadas ou queijos de pasta mole. Este vinho pode criar depósito.}

Segmentos como este introduzem no gênero e, especificamente, no texto, outra espécie de atividade de linguagem: a atividade enológica. Isto se confirma, aliás, pela presença do nome e da assinatura do enólogo. Contudo, a atividade enológica não se situa no mesmo plano ou nível que as atividades comercial e publicitária. De fato, esses gêneros da enologia (notas de prova, recomendações de consumo e serviço do vinho) surgem subordinados às dimensões comercial e publicitária. De modo que, para analisar textos desse gênero rótulo, é preciso observar o feixe de atividades que se interligam de formas diversas: ora em rede, ora em forma hierárquica. Uma possibilidade é conceber uma organização como a que se apresenta no seguinte esquema:

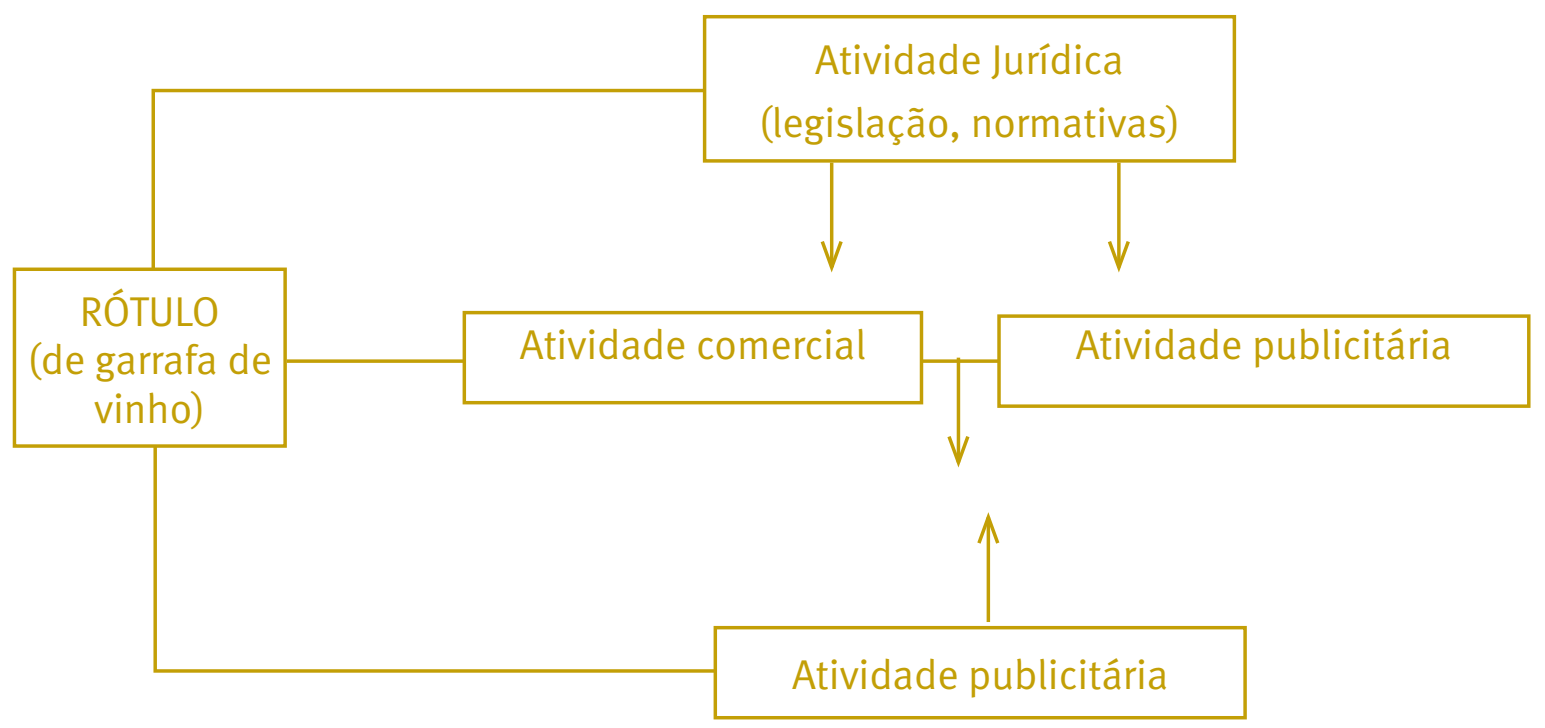

Esses exemplos demonstram que a relação entre atividades e gêneros é muito mais complexa e dinâmica do que uma simples relação termo a termo ou biunívoca. Além disso, demonstram que o problema não é apenas que 
um mesmo gênero pode estar associado a diferentes domínios, mas que um gênero pode combinar de formas diversas diferentes atividades de linguagem.

O último aspecto que me interessa apresentar muito brevemente também diz respeito ao funcionamento dos gêneros na dinâmica das práticas de linguagem. Admitindo que o processo de produção textual implica a atualização de um modelo de gênero que é adotado e adaptado (BRONCKART, 1997, 2004a), os traços semióticos dos gêneros podem, no entanto, ser objeto de um processo de imitação ou, mais especificamente, de ficcionalização, tal como propus no quadro da minha tese sobre o processo de intertextualização (cf. MIRANDA, 2007 e 2010). É isso o que exemplificam os textos (3) e (4).

O texto (3) é um cartum que ficcionaliza um cartaz de filme e o texto (4) é um anúncio publicitário que ficcionaliza uma bula de remédio. Podemos identificar isso pela presença de traços próprios dos gêneros simulados. Para esses traços, utilizo a expressão “marcadores genéricos” (cf. MIRANDA, 2007 e 2010).

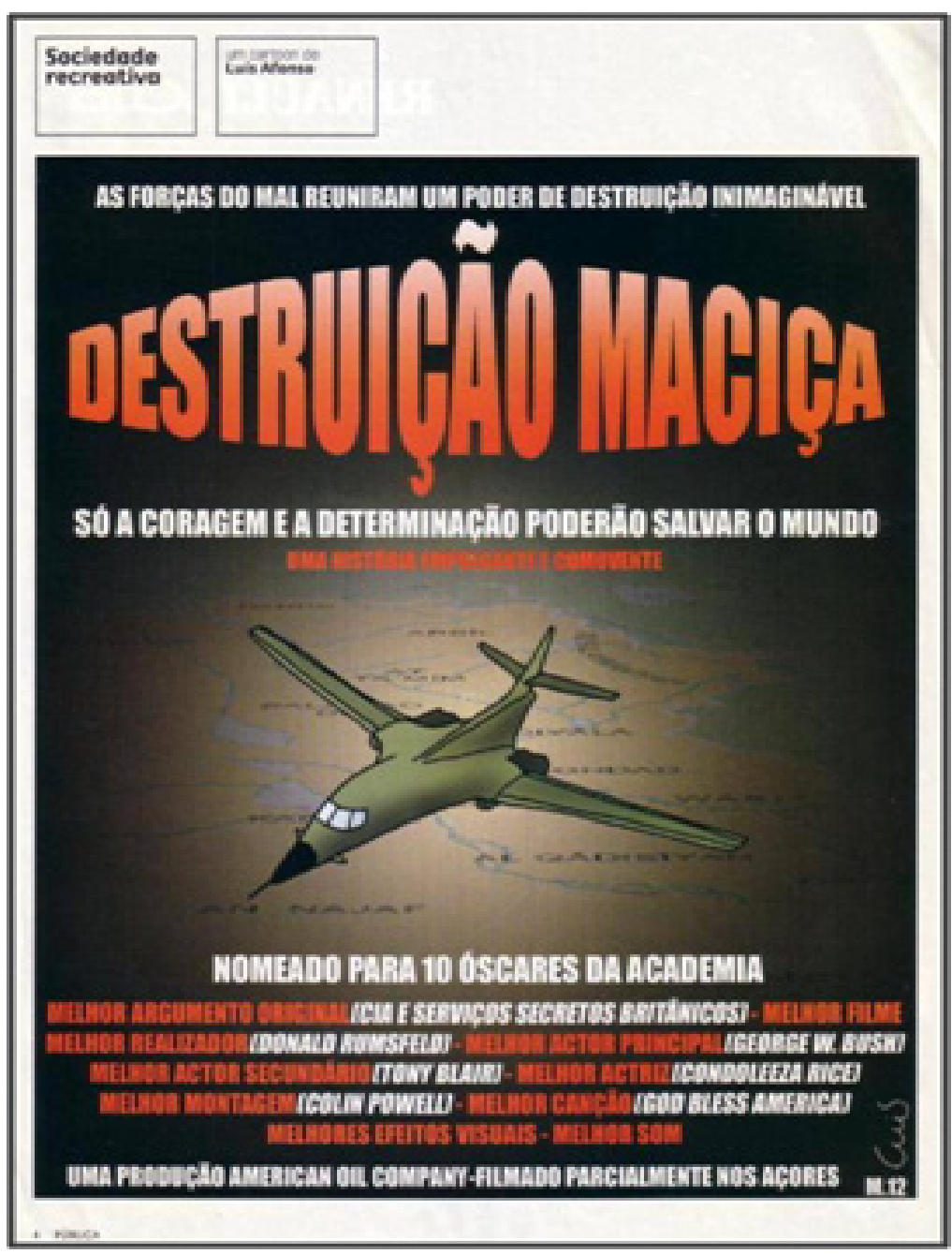

Texto (3) 
No caso do texto (3), por exemplo, reconhecemos um conjunto variado de marcadores. Vejamos alguns deles. Há, no que diz respeito à organização composicional, um plano de texto que se caracteriza pelas seguintes propriedades: 1) presença de uma imagem em posição central e de uma série de enunciados breves distribuídos na região superior e na região inferior do texto; 2) um dos enunciados é destacado graficamente pela tipografia, pela cor e pela localização na página (“destruição maciça”); 3) na região inferior há um segmento relativamente longo composto por uma enumeração; 4) a relação entre a imagem e os segmentos verbais é basicamente de ilustração (pois a imagem não complementa, substitui ou repete as informações dos enunciados).

Além disso, podemos observar a ocorrência de um número elevado de frases nominais e a ocorrência de frases verbais reduzidas de particípio. As frases verbais desenvolvidas surgem em menor número. Corresponde também ao plano da composição, a identificação de uma organização sequencial de tipo descritivo, na qual se realizam essencialmente as operações de ancoragem (“destruição maciça” na função de tema-título) e aspectualização.

No âmbito da organização temática, encontramos um campo semântico saliente, constituído pelo léxico associado à cinematografia: argumento original, filme, realizador, ator principal, montagem, efeitos visuais, etc. Também fazem parte desse conjunto as expressões ritualizadas "nomeado para X óscares da academia", "uma produção X" e "filmado em X". Mais ainda: note-se a ocorrência reiterada do qualificador "melhor", antecedendo os substantivos relativos ao campo cinematográfico.

É claro que estes não são os únicos marcadores do gênero convocado no texto. Todavia, esses elementos parecem suficientes para a identificação do processo de ficcionalização do gênero cartaz publicitário de filme cinematográfico.

Já no texto (4) reconhecemos certos aspectos da organização temática que funcionam como pistas para a identificação da bula de remédio, tais como o emprego de determinado vocabulário específico: posologia, propriedades, efeitos secundários, recomendações e indicações. Também, cada um destes termos funciona, no plano da organização composicional global, como um título ou introdutor de uma seção do plano de texto convencional do gênero bula. Por outro lado, há traços da disposição das seções e do aspecto material que também são recorrentes na bula: a apresentação do material verbal em colunas, a diversidade tipográfica sóbria (diferente tamanho ou grossor para um mesmo tipo de letra) ou, inclusive, as barras horizontais e verticais nas margens. 
Meu objetivo aqui não é aprofundar a análise, ${ }^{4}$ o que me interessa salientar destes exemplos é o fato de os gêneros poderem ser objeto de um processo particular de reutilização dos traços semióticos que lhes estão associados. Com efeito, somos capazes de identificar que há nesses textos a imitação dos gêneros cartaz e bula de remédio, embora os textos atualizem outros gêneros diferentes (o cartum e o anúncio).

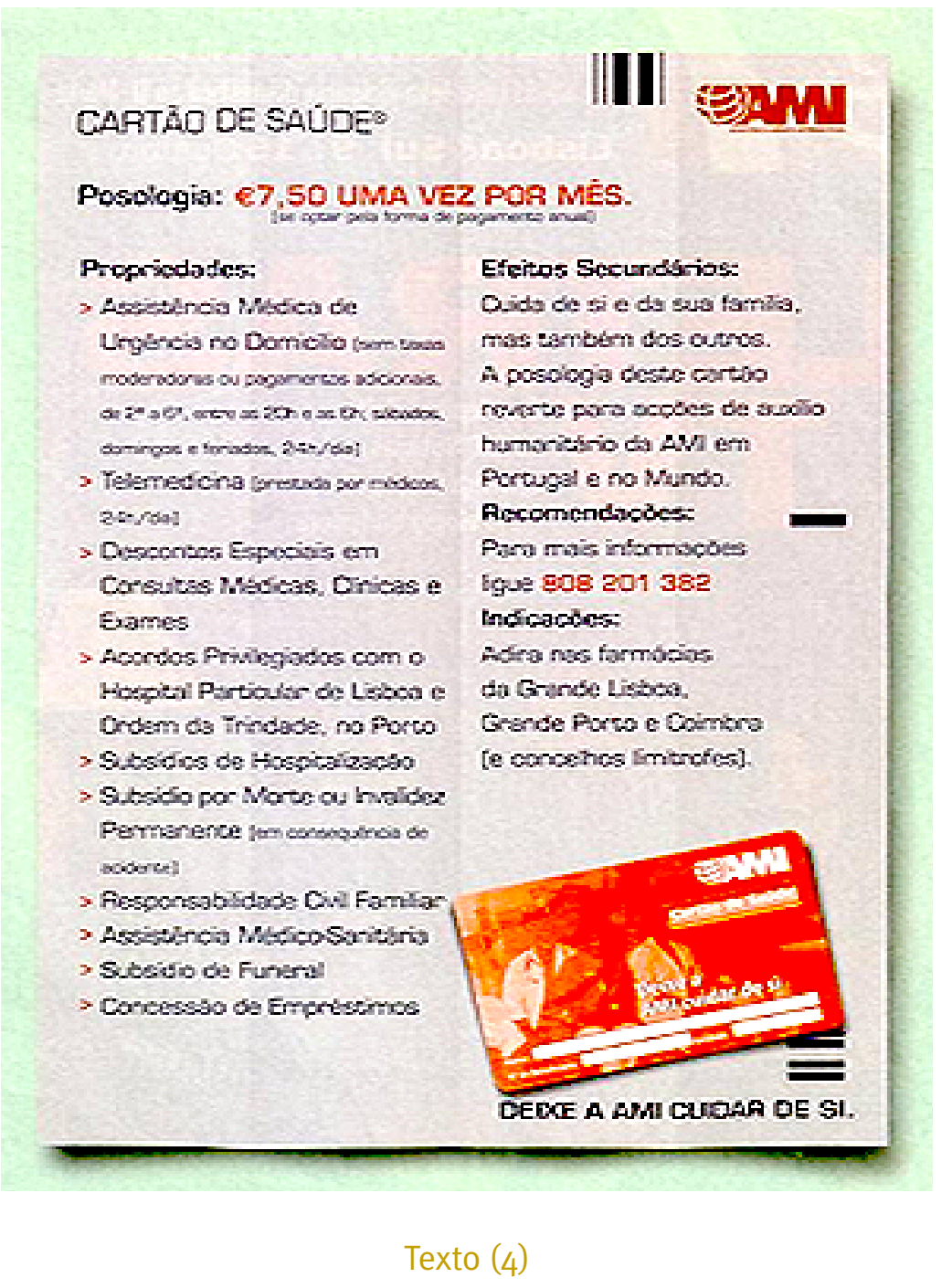

Esta possibilidade de os gêneros serem reutilizados como formas semióticas desligadas do seu contexto original talvez possa ser compreendida a partir das considerações de Bronckart quando afirma que, como outras obras humanas, os gêneros "podem se separar das motivações que lhes deram origem, para se tornarem autônomos e, assim, ficarem disponíveis para a expressão de outras finalidades" (BRONCKART, 2006, p. 144).

Para uma análise pormenorizada destes textos e para uma discussão acerca do processo de ficcionalização de gêneros, ver MIRANDA (2007 e 2010). 


\section{CONSIDERAÇõES FINAIS}

Para finalizar esta reflexão, proponho três interrogações finais e alguns ensaios de respostas.

Em primeiro lugar, e depois de toda a problematização, me pergunto se é realmente possível e necessário inventariar os diversos domínios de atividade. Sem dúvida, para o avanço de algumas pesquisas ou para algumas situações de ensino pode ser necessário identificar os possíveis domínios de atividade. Em qualquer caso, como sublinha Bronckart (2008, p. 46), essa distinção não se pode realizar na base de critérios linguísticos. Mas, por outro lado, se observarmos a lista proposta por Marcuschi, por exemplo, ou ainda a listagem de lugares sociais proposta em (BRONCKART et al., 1985, p. 33), ${ }^{5}$ sentiremos que há uma verdadeira redução da enorme diversidade, da mobilidade e das interligações das práticas reais. A meu ver, e concordando com Bronckart (2008, p. 46), nenhum inventário conseguiria exprimir essa diversidade e heterogeneidade, de modo que qualquer listagem apenas pode ser indicativa e aproximada.

Em segundo lugar, podemos perguntar se é possível e necessário inventariar os gêneros associados a uma determinada atividade. Mais uma vez, isso talvez seja necessário para algumas abordagens empíricas (por exemplo, de novo, no âmbito de determinadas pesquisas ou em situações de ensino). Contudo, sempre será um recorte artificial, parcial e, provavelmente, redutor.

Em terceiro lugar, pergunto que consequências metodológicas para a análise dos gêneros e dos textos surgem a partir da impossibilidade de classificação ou tipologização definitiva das atividades e, sobretudo, da instabilidade da relação entre os gêneros e as atividades. Penso que a consequência principal é que no estudo dos textos e dos gêneros (ou no seu ensino) não devemos tentar identificar a que atividade particular estão associados, mas devemos,

Essa listagem inclui as seguintes instituições e lugares: Institutions économinques et commerciales, Institution étatico-politique, Institution littéraire (ou "littérature"), Institution académico-scientifique, Institution de soin, Institutions de répression (justice et police), Institution scolaire, Institution familiale, Institutions médiatiques, Lieu des pratiques de loisirs, Lieu des pratiques de contact quotidien [em francês, no original : Instituições econômicas e comerciais, Instituições político-estatais, Instituição literária (ou "literatura"), Instituição acadêmico-científica, Instituição de cuidado, Instituição de repressão (justição e política), Instituição escolar, Instituição familiar, Instituições midiáticas, Lugares de práticas de lazer, Lugares de práticas de contato cotidiano. Trad. dos editores]. 
antes, indagar a rede de atividades que influenciam (de modos diferentes) essas formas de organização da linguagem. Em última análise, o nosso trabalho deve ser, também, explorar e mostrar as tensões do funcionamento dos gêneros (realizados em textos) na dinâmica das práticas coletivas e singulares. 


\section{Text genres in the dynamic of language practices}

\section{ABSTRACT}

The notion of genre (textual or discursive) occupies an important place in the different approaches used inside of language sciences insofar as genres are conceived as relatively stable manners of establishing the nexuses between unique texts and the activities of social life. However, the relationships between genres and activities are the object of discussion in many scientific positions. This paper is concerned with contributing to this debate, starting with the use of a critical dialogue between the textual semantics of François Rastier and the socio-discursive interactionism of Jean-Paul Bronckart and through analysis of three texts. Its central purpose is to show that biunvocal and simple relationships cannot be established between practical activities and genres, since many activities can be implied in just one genre and, reciprocally, a single genre can be mobilized in different activities of social life.

\section{KEYWORDS}

Text genres. Genres of discourse. Activity of language. Socio-discursive interactionism. Text semantics. 


\section{REFERÊNCIAS}

ADAMZIK, Kristen. Le début du texte. Le titre et les premières phrases, dans les textes académiques, Cahiers de Linguistique Française, Genebra, n. 20, p. 31-64, 1998.

BAZERMAN, Charles. Atos de fala, gêneros textuais e sistemas de atividades: como os textos organizam atividades e pessoas. In: Gêneros textuais, Tipificação e Interação. São Paulo: Cortez, 2004. p. 83-99.

BHATIA, Vijay. Worlds of written discours. London: Continuum, 2004.

BRONCKART, Jean-Paul. Activité langagière, textes et discours. Pour un interactionisme socio-discursif. Lausanne: Delachaux et Niestlé, 1997.

BRONCKART, Jean-Paul. et al. Le fonctionnement des discours : un modèle psychologique et una méthode d'analyse. Paris: Delachaux et Niestlé, 1985.

BRONCKART, Jean-Paul. Genres de textes, types de discours e " degrés » de langue. Hommage à François Rastier, Texto!, Publicação on line, v. 13, n. 1/2, 2008. Disponível em http://www.revue-texto.net/index.php?id=86. Acesso em: 09/01/2009

BRONCKART, Jean-Paul. Les genres de textes et leur contribution au développement psychologique, Langages, Paris, n. 153, p. 98-108, $2004 a$.

BRONCKART, Jean-Paul. Os gêneros de textos e os tipos de discurso como formatos das interações propiciadoras de desenvolvimento. In: BRONCKART, Jean-Paul. Atividade de linguagem, discurso e desenvolvimento humano. Campinas: Mercado de Letras, 2006. p.121-160.

BRONCKART, Jean-Paul. Pourquoi et comment analyser l'agir verbal et non verbal en situation de travail, Cahiers de la section des Sciences de l'Education, Genebra, n.103 (Agir et discours en situation de travail), p.11-144, 2004b.

DEVITT, Amy. Intertextuality in tax accounting: Generic, referential and functional. In Charles Bazerman \& James Paradis (eds.) Textual dynamics of the Professions. Madison: University of Wisconsin Press, pp. 336-380, 1991.

MARCUSCHI, Luiz Antônio. Produção textual, análise de gêneros e compreensão. São Paulo: Parábola, 2008.

MIRANDA, Florencia. Aspectos de la organización (semio)lingüística de 
etiquetas de vino (portugués y español). In: CARIELLO, G. etal. Tramos y Tramas III. Culturas, lenguas, literaturas e interdisciplina. Estudios comparativos. Rosario: Laborde, 2011. p.121-128.

MIRANDA, Florencia. Textos e géneros em diálogo: uma abordagem linguística da intertextualização. (Tese de Doutorado) - Universidade Nova de Lisboa, Lisboa, 2007.

MIRANDA, Florencia. Textos e géneros em diálogo: uma abordagem linguística da intertextualização. Lisboa: FCG-FCT, 2010.

MIRANDA, Florencia; COUTINHO, Maria Antónia. Las etiquetas como género de texto - un abordaje comparativo". In: II Congreso sobre la Lengua de la Vid y el Vino, y su Traducción. Soria: Universidad de Valladolid, 2008. Disponível em: [http://www.clunl.edu.pt/resources/docs/Grupos/Gramatica/equipa/ antoniacoutinho/florencia\%20 miranda $\% 20 \% \% 20$ maria\%20antonia $\% 20$ coutinho.pdf]. Acesso em: 09/01/2009

RASTIER, François. Arts et sciences du texte. Paris: PUF, 2001.

RASTIER, François. Sens et textualité. Paris: Hachette, 1989.

VOLOSHINOV, Valentin N. El marxismo y la filosofía del lenguaje. Buenos Aires: Ediciones Godot, 2009. 